\title{
Effects of Land Use Changes on Ecosystem Service Values: A Case Study in Guilin, China
}

\author{
Lili Zhao, Xuncheng Fan* \\ College of Urban and Rural Construction, Shaoyang University, Shaoyang, China
}

Received: 14 February 2019

Accepted: 14 April 2019

\begin{abstract}
Based on the Landsat 5 TM/Landsat 8 OLI images of Guilin City in 2002, 2012, and 2017, the objectoriented land use classification method and mathematical models (such as transfer matrix and dynamic degree), as well as the Chinese ecosystem service unit area value equivalent factor table, were used to quantifiably analyze the land use status and changes in the value of ecosystem services in Guilin from 2002 to 2017. The results showed that forest land was the main matrix type in the study area. During the study period, forest land and unused land were the types of land that had increased and decreased the most, respectively, while the reduced unused land was mainly transferred to forest land and cultivated land. The changes in unused land and construction land were particularly intense, and the land use changes of Guilin as a whole continued to increase during the study period. The value of ecosystem services in Guilin continued to rise, and the value of ecosystem services on forest land accounts for more than $85 \%$ of the entire ecosystem. The value of services such as soil formation and protection, water conservation, and biodiversity conservation were higher within the value of each individual service. In contrast, services such as food production had the lowest value, indicating that the service function of Guilin's ecosystem was far greater than the productive function.
\end{abstract}

Keywords: Landsat 8, ecotourism, GIS, object-oriented classification, international scenic city

\section{Introduction}

Land use is the way that human beings obtain economic benefits from land through land transformation and utilization in order to survive and develop [1]. Land use change is the result of the interaction between humans and nature [2-4]. It transforms land that was originally a natural attribute into an artificial ecosystem with social attributes. "Land use types" refers to a combination of natural or artificial surface coverings that undergo various changes in form and state, such as

*e-mail: syl12018@126.com buildings (houses, roads, etc.), soil, surface vegetation, glaciers, rivers, and wetlands [5-6]. A land use change is essentially a change in the area and spatial location; that is, a change in the area and spatial patterns of various ecosystem types. Land use classification mapsusually are used to study the spatial-temporal variation characteristics of land use [7-9].

Ecosystem services are products and services that can support life activities. They can be directly or indirectly obtained via the structures, processes, and functions of ecosystems [10-11]. Human beings both live in ecosystems and accept the gifts of ecosystems all the time, while releasing harmful substances into ecosystems. This can lead to ecosystem disorder, 
which makes an ecosystem unable to resume normal operation;this ultimately affects human survival and development [12-14]. Land use change not only causes changes in the environments on which humans depend, but also affects the structure and function of the Earth's biosphere, chemical circle, and physical circle [15]. It also causes imbalances in ecosystem material flow and energy flow, resulting in a sharp decline in biodiversity and global warming [16-17]. Land use is one of the most closely related links between man and nature. The relationship between land use change and ecosystem service function is very close. They are a pair of contradictory entities. Therefore, it is of great significance to study land use changes as well as the value of ecosystem services for the sake of protectingregional ecosystem services.

Guilin is a world-famous international scenic city in China. The Chinese government has been vigorously developing tourism in Guilin since 2012. In 2017, the number of tourists in Guilin reached 82.33 million, and total tourism consumption was 97.18 billion yuan. The influx of a large number of tourists and the rapid economic growth inevitably led to changes in land use and the value of ecosystem services, thus affecting the tourism environment and ecological security of Guilin [18-19]. Therefore, in this study, remote sensing images from 2002, 2012, and 2017 were used to study the impact of land use changes on the value of ecosystem services in Guilin in order to provide a reference for the rational development and utilization of land resources and the sustainability of the ecological environment.

\section{Materials and Methods}

Study Area

Guilin $\left(24^{\circ} 15^{\prime}-26^{\circ} 23^{\prime} \mathrm{N}, 109^{\circ} 36^{\prime}-111^{\circ} 29^{\prime} \mathrm{E}\right)$ is located in northeastern Guangxi Province, southwestern
China. It governs 11 counties and 6 municipal districts, and covers an area of more than $27,800 \mathrm{~km}^{2}$ (Fig. 1). It has a subtropical monsoon climate with an average temperature of $23^{\circ} \mathrm{C}$, average annual rainfall of $1949.5 \mathrm{~mm}$, and average annual sunshine of 1670 hours. The terrain is mainly medium and low mountains. The karst landform is perfectly developed, the landscape is peculiar, and the resident population was more than 5 million in 2017. In 2014, the South China karst landform represented by Guilin appeared on UNESCO's World Natural Heritage List.

\section{Source and Processing of the Remote Sensing Images}

The remote sensing images from Landsat 5-TM and 2017 Landsat 8-OLI of Guilin City in 2002, 2012, and 2017 were derived from the geospatial data cloud platform of the Chinese Academy of Sciences with a resolution of $30 \mathrm{~m}$. Owing to the influence of the atmosphere on electromagnetic radiation, the curvature of the Earth, terrain fluctuations, and the sensor itself, the information received by the terrestrial satellite platform is inconsistent with the actual situation. This requires preprocessing of the data acquired by the satellite to restore the real information. The preprocessing of the remote sensing data in this study was divided into the stages of radiation correction, geometric correction, image mosaic, and clipping.

\section{Radiation Correction}

Radiation correction is divided into systemical radiation correction and atmospheric radiation correction. Satellite images were downloaded via the geospatial data cloud platform of the Chinese Academy of Sciences; they had been systemically calibrated, so they only needed to be corrected for atmospheric

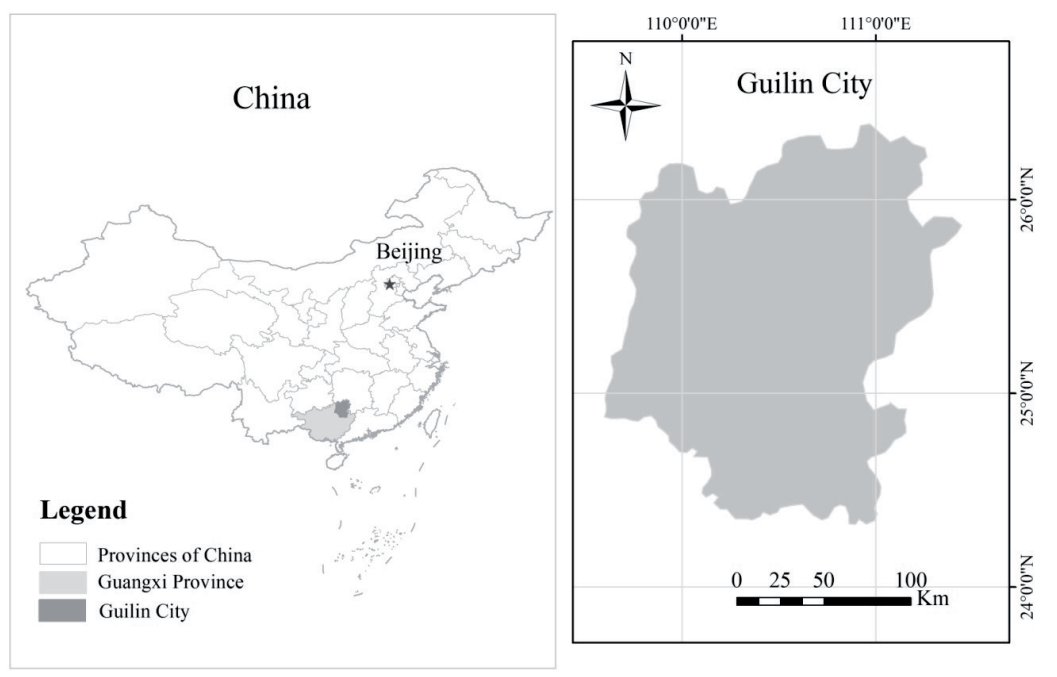

Fig. 1. Map of the study area. 
radiation. In this study, the FLAASH atmospheric correction module in the ENVI 5.2 software was used to correct the images of the study area from 2002, 2012, and 2017.

\section{Geometric Correction}

Geometric correction is divided into geometric rough correction and geometric fine correction. The remote sensing images used in this study had already undergone geometric rough correction. In order to ensure the accuracy of the research, the remote sensing images were calibrated via geometric fine correction. Firstly, based on a topographic map of Guilin and Google Earth satellite images, the remote sensing image from 2002 was geometrically corrected using cubic polynomial interpolation. Thirty ground control points were selected and evenly distributed in the study area, and the error was controlled to within a pixel. Then the remote sensing images from 2012 and 2017 were corrected based on the 2002 image.

\section{Determining the Band}

In this study, the principal component analysis method was used to analyze the data of each band of the remote sensing images in order to determine the band with less correlation and a greater amount of information. Research has shown that RGB that is 5, 4, and 3 bands can meet the requirements. Therefore, the color synthesis of the study area was carried out using the 5, 4, and 3 bands.

\section{Mosaic and Clipping}

The image with the largest area was placed on top as a reference image during the mosaic process. The histogram matching method was used for the mosaic in order to eliminate the difference in the imaging time, illumination, and atmospheric state of each image. After each image was inlaid, the vector graphics of the study area were imported, and the clipping was performed; finally, the remote sensing image maps of each period were obtained.

\section{Object-Oriented Classification Method of Land Use}

Compared with other classification methods, the object-oriented classification method aims at objects rather than pixels, and makes full use of objectoriented information (such as hue and hierarchy) and inter-class information (such as adjacent objects). Land use is classified according to the spatial and spectral characteristics of the selected objects, making the land use information more intelligent and accurate, which complements the pixel-level classification. Therefore, the land use classification in the study area was carried out using the object-oriented method. After experiment and comparison, the scale level and merge level were set to 20 and 80 , respectively, so as to segment the ground features with smooth transitions and ensure that the same feature was not divided into several objects. A good classification result can be achieved by selecting 250 samples for each type of land use over repeated trials. Finally, land use classification maps of the study area in 2002, 2012, and 2017 were obtained via the object-oriented classification method (see Fig. 2).

\section{Method for Studying Land Use Changes}

The mathematical models of land use change used in this study included the transfer matrix model and the dynamic degree model. The land use transfer matrix is a common method for studying the characteristics, direction, and structure of land use change. It can express not only the structural characteristics of land use, but also the source and composition of various types within the study period. In addition, the transfer matrix can also generate a transition probability matrix, indicating that various land use types can be sorted by percentage. From the sorting, the main land use types and secondary types that cause the change of specific land use type can be seen, allowing an analysis of the reason for the changes in this specific land use type. The mathematical formula of the land use transfer matrix is the as follows:

$$
P_{i j}=\left[\begin{array}{cccc}
P_{11} & P_{12} & \cdots & P_{1 n} \\
P_{21} & P_{22} & \cdots & P_{2 n} \\
\vdots & \vdots & \vdots & \vdots \\
P_{n 1} & P_{n 2} & \cdots & P_{n n}
\end{array}\right]
$$

...where $P$ represents the area, $n$ represents the number of land use types, and $i$ and $j$ represent the land use types at the beginning and end of the study period, respectively.

The land use dynamic degree model is commonly used for portraying changes in the amount of land resources and reflecting the intensity of land use change [20-21]. The land use changes in Guilin in this study were calculated using two models of single land use type dynamic degree and comprehensive land use dynamic degree.

The dynamic degree of single land use type reflects the average annual rate of change of a land use type during the study period. It can be expressed by the following formula:

$$
\mathrm{K}=\left[\left(U_{b}-U_{a}\right) / U_{a}\right] \times T^{-1} \times 100 \%
$$

...where $K$ is the dynamic degree of a specific land use type; $U_{a}$ and $U_{b}$ are the area of a land use type at the beginning and end of the study, respectively; $T$ is the length of time of the study; and its unit is $a$. 
Table 1. Equivalent value per unit area of terrestrial ecosystem services in China.

\begin{tabular}{|c|c|c|c|c|c|c|}
\hline Indicators & Forestland & Grassland & Cultivated land & Wetland & Water area & Barren land \\
\hline Gas regulation & 3.50 & 0.80 & 0.50 & 1.80 & 0.00 & 0.00 \\
\hline Climate regulation & 2.70 & 0.90 & 0.89 & 17.10 & 0.46 & 0.00 \\
\hline Water conservation & 3.20 & 0.80 & 0.60 & 15.50 & 20.38 & 0.03 \\
\hline Soil formation and protection & 3.90 & 1.95 & 1.46 & 1.71 & 0.01 & 0.02 \\
\hline Waste treatment & 1.31 & 1.31 & 1.64 & 18.18 & 18.18 & 0.01 \\
\hline Biodiversity conservation & 3.26 & 1.09 & 0.71 & 2.50 & 2.49 & 0.34 \\
\hline Food production & 0.10 & 0.30 & 1.00 & 0.30 & 0.10 & 0.01 \\
\hline Supply of raw materials & 2.60 & 0.05 & 0.10 & 0.07 & 0.01 & 0.00 \\
\hline Entertainment and culture & 1.28 & 0.04 & 0.01 & 5.55 & 4.34 & 0.01 \\
\hline
\end{tabular}

The comprehensive land use dynamic degree reflects the stability of land use change in the study area. The higher the value, the more active the land use change in the area and the worse the stability. Its model is as follows:

$$
K_{s}=\sum_{i=1}^{n}\left|U_{b i}-U_{a i}\right| / 2 \sum_{i=1}^{n} U_{a i} \times T^{-1} \times 100 \%
$$

...where $K_{s}$ is the comprehensive dynamic degree of Guilin; $U_{a i}$ and $U_{b i}$ are, respectively, the area of a specific land use type at the beginning and end of the study; $n$ is the number of land use types; and $T$ is the length of time for the study period.

\section{Selection and Value Calculation of Ecosystem Services}

In the selection of ecosystem service indicators we referred to the research results of Xie et al. [22], which are widely used and recognized by domestic scholars
[23-24]; they cover gas regulation, climate regulation, water conservation, soil formation and protection, waste treatment, biodiversity conservation, food production, supply of raw materials, and entertainment culture.

Xie et al. [25], based on the research results of Costanza et al. [26] combined with the actual situation in China, established a table of equivalent value per unit area of terrestrial ecosystem services. It provides a reference for the calculation of China's ecosystem service value and is convenient to researchers (see Table 1).

According to the equivalent table, and combined with the six land use types in this study, Table 1 was slightly modified to make a table of the equivalent value per unit area value of ecosystem services in Guilin City, as shown in Table 2.

In this study, the land use types were divided into six types: forest land, cultivated land, water, unused land, grassland, and construction land. However, construction land was not included in Table 2 because the ecosystem services are a positive effect on humans. However, construction land, such as rural residential land and urban industrial and mining landcauses great damage

Table 2. Equivalent weighting factor of ecosystem services valueper hectare of terrestrial ecosystem in Guilin.

\begin{tabular}{|c|c|c|c|c|c|}
\hline Types & Forest land & Cultivated land & Water & Unused land & Grassland \\
\hline Gas regulation & 3.50 & 0.50 & 0.00 & 0.00 & 0.80 \\
\hline Climate regulation & 2.70 & 0.89 & 0.46 & 0.00 & 0.90 \\
\hline Water conservation & 3.20 & 0.60 & 20.38 & 0.03 & 0.80 \\
\hline Soil formation and protection & 3.90 & 1.46 & 0.01 & 0.02 & 1.31 \\
\hline Waste treatment & 1.31 & 1.64 & 18.18 & 0.01 & 1.95 \\
\hline Biodiversity conservation & 3.26 & 0.71 & 2.49 & 0.34 & 1.09 \\
\hline Food production & 0.10 & 1.00 & 0.10 & 0.01 & 0.30 \\
\hline Supply of raw materials & 2.60 & 0.10 & 0.01 & 0.00 & 0.05 \\
\hline Entertainment and culture & 1.28 & 0.01 & 4.34 & 0.01 & 0.04 \\
\hline
\end{tabular}


Table 3. Area changes of different land use types from 2002 to 2017 in Guilin $\left(\mathrm{km}^{2}\right)$.

\begin{tabular}{|c|c|c|c|c|c|c|c|c|c|}
\hline \multirow{2}{*}{ Types } & \multicolumn{2}{|c|}{2002} & \multicolumn{2}{|c|}{2012} & \multicolumn{2}{|c|}{2017} & $2002-2012$ & $2012-2017$ & $2002-2017$ \\
\cline { 2 - 11 } & $\begin{array}{c}\text { Area } \\
/ \mathrm{km}^{2}\end{array}$ & $\begin{array}{c}\text { Propor- } \\
\text { tion/\% }\end{array}$ & $\begin{array}{c}\text { Area } \\
/ \mathrm{km}^{2}\end{array}$ & $\begin{array}{c}\text { Propor- } \\
\text { tion} / \%\end{array}$ & $\begin{array}{c}\text { Area } \\
/ \mathrm{km}^{2}\end{array}$ & $\begin{array}{c}\text { Propor- } \\
\text { tion/\% }\end{array}$ & $\begin{array}{c}\text { Net } \\
\text { change } \\
/ \mathrm{km}^{2}\end{array}$ & $\begin{array}{c}\text { Net } \\
\text { change } \\
/ \mathrm{km}^{2}\end{array}$ & $\begin{array}{c}\text { Net } \\
\text { change } \\
/ \mathrm{km}^{2}\end{array}$ \\
\hline Construction land & 890.96 & 3.20 & 950.19 & 3.42 & 1065.78 & 3.83 & 59.23 & 115.59 & 174.82 \\
\hline Forest land & 16933.44 & 60.89 & 17440.23 & 62.71 & 18162.56 & 65.31 & 506.79 & 722.33 & 1229.12 \\
\hline Water & 710.56 & 2.56 & 700.46 & 2.52 & 720.52 & 2.59 & -10.10 & 20.06 & 9.96 \\
\hline Cultivated land & 3842.89 & 13.82 & 3978.12 & 14.30 & 4026.65 & 14.48 & 135.23 & 48.53 & 183.76 \\
\hline Unused land & 5114.23 & 18.39 & 4512.36 & 16.23 & 3517.92 & 12.65 & -601.87 & -994.44 & -1596.31 \\
\hline Grassland & 317.78 & 1.14 & 228.49 & 0.82 & 316.42 & 1.14 & -89.29 & 87.93 & -1.36 \\
\hline
\end{tabular}

to the natural ecological environment and continuously discharges sewage, waste gas, and solid waste into the environment. Therefore, it mainly has a negative effect on the ecological environment. For this reason, the value of ecosystem services for construction land was not calculated in this study.

The service value per unit area of cultivated land ecosystem in Guilin City was calculated using equation 4:

$$
E_{a}=\frac{1}{7} \times T_{a} \times T_{b}
$$

...where $E_{a}$ denotes the service value per hectare of cultivated land in the study area (yuan $\left./ \mathrm{hm}^{2}\right), T_{a}$ represents the average grain yield $\left(\mathrm{kg} / \mathrm{hm}^{2}\right)$, and $T_{b}$ is the average purchase price of grain in China.

The value of grain is volatile, and there is a difference in the average purchase price of grain per year. In this study, the service value per hectare of cultivated land was calculated using the average purchase price of grain in China $\left(T_{b}, 2.77\right.$ yuan $\left./ \mathrm{kg}\right)$ and the average grain yield in Guilin $\left(T_{a}, 2737.56 \mathrm{~kg} / \mathrm{hm}^{2}\right)$ in 2017.

The service value per unit area of other ecosystems can be obtained via Table 1 and Formula 5:

$$
C V_{i j}=E_{a} \times f_{i j}
$$

...where $C V_{i j}$ is a specific ecosystem service unit area value (yuan $/ \mathrm{hm}^{2}$ year) and $f_{i j}$ is the equivalence factor of a specific ecosystem service of a specific land use type.

The total ecosystem service value can be calculated using Formula 6:

$$
E S V=\sum_{i=1}^{n} \sum_{j}^{m} A_{i} \times C V_{i j}
$$

...where $E S V$ denotes the total ecosystem service value (yuan) and $A_{i}$ represents the area of a specific land use type.

\section{Results and Discussion}

\section{Area Changes of Land Use Types}

As can be seen from Table 3, forest land was the main matrix type in Guilin and it accounted for more than $60 \%$ of the total area of Guilin in 2002, 2012, and 2017. From 2002 to 2017, the area of forest land, cultivated land, construction land, and water increased, while the area of unused land and grassland decreased. Furthermore, the area of forest land has increased the
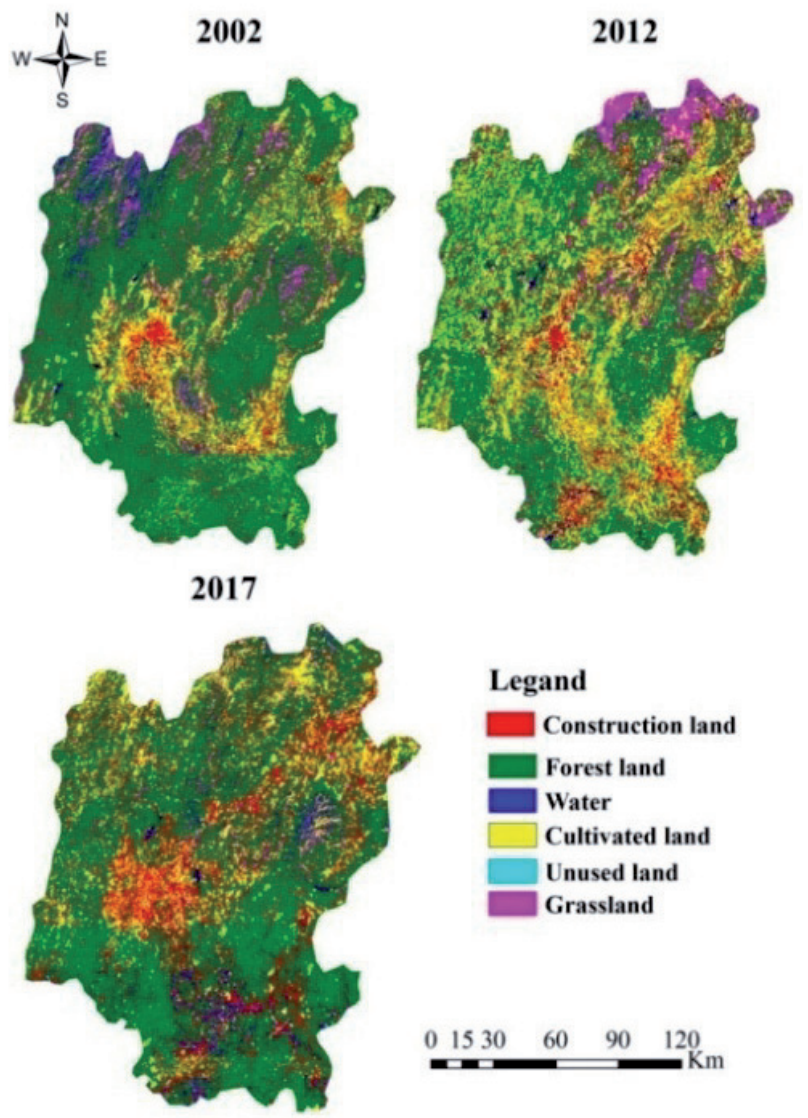

Fig. 2.Spatial distribution of various land use types in the study area from 2002 to 2017. 
Table 4. Land use transfer probability matrix from 2002 to 2017 in Guilin (\%).

\begin{tabular}{|c|c|c|c|c|c|c|}
\hline 2017 & Construction land & Forest land & Water & Cultivated land & Unused land & Grassland \\
\hline Construction land & 10.28 & 1.69 & 5.34 & 5.28 & 6.26 & 0.92 \\
\hline Forest land & 49.83 & 76.52 & 60.89 & 47.35 & 34.03 & 50.80 \\
\hline Water & 3.45 & 3.40 & 14.54 & 1.72 & 1.66 & 0.48 \\
\hline Cultivated land & 25.40 & 7.86 & 12.03 & 25.48 & 30.23 & 11.30 \\
\hline Unused land & 0.11 & 0.03 & 0.05 & 0.45 & 2.75 & 0.35 \\
\hline Grassland & 10.93 & 10.50 & 7.16 & 19.72 & 25.07 & 36.15 \\
\hline
\end{tabular}

Table 5. Dynamic degree of various land use types in Guilin (\%).

\begin{tabular}{|c|c|c|c|}
\hline Types & $2002-2012$ & $2012-2017$ & $2002-2017$ \\
\hline Construction land & 0.66 & 2.43 & 1.31 \\
\hline Grassland & -2.81 & 7.70 & -0.03 \\
\hline Unused land & -1.18 & -4.41 & -2.08 \\
\hline Forest land & 0.30 & 0.83 & 0.48 \\
\hline Water & -0.14 & 0.57 & 0.09 \\
\hline Cultivated land & 0.35 & 0.24 & 0.32 \\
\hline
\end{tabular}

most over 15 years, with an increase of $1229.12 \mathrm{~km}^{2}$, and the area of unused land has decreased the most, with a decrease of $1596.31 \mathrm{~km}^{2}$.

The area changes of other land use types from 2012 to 2017 were greater than those from 2002 to 2012, except for cultivated land and grassland, indicating that the changes were more severe in various land use types in the last 5 years than those in the previous 10 years. The Chinese government has been vigorously developing the tourism industry in Guilin since 2012, resulting in significant area changes in land use types. In contrast, the area increase of the cultivated land in the previous 10 years was more significant than in the last 5 years. Meanwhile, the area of grassland showed a decreasing trend in the previous 10 years, and an increasing trend in the last 5 years.

\section{Transfer Matrix of Land Use Types}

In the study of land use change, an increase or decrease of the area of land use types cannot reflect the transformation information among different types of land, while the land use transfer matrix can effectively reveal the specific conversion among land use types [27]. Based on the results of remote sensing classification (Fig. 2), the land use transfer matrix of the study area was obtained using ENVI classic 5.2.

Table 4 shows that the retention rate of forest land is the highest during the study period, with a value of $76.52 \%$, and the transfer rate of other land types to forest land is higher than $34 \%$, which is the main reason for the rapid increase in the area of forest land during the study period. However, the retention rate of unused land is only $2.75 \%$, and the transfer rate is as high as $97.25 \%$, mainly shifting to forest land and cultivated land. The cultivated land area showed an increasing trend during 15 years because unused land and construction land transferred $30.23 \%$ and $25.40 \%$, respectively, to cultivated land.

\section{Dynamic Degree of Land Use Types}

Table 5 shows that construction land had the highest dynamic degree, with a value of $1.31 \%$ during 15 years. The dynamic degree from 2012 to 2017 was 2.43\%, while the value in the first 10 years (2002-2012) was only $0.66 \%$. This shows that the speed of the area increase in construction land in the last 5 years has obviously accelerated. The dynamic degree of grassland in the past 15 years was only $-0.03 \%$. However, from 2012 to 2017 the dynamic degree value was as high as 7.70\%, indicating that the grassland area increased rapidly during these five years. This was mainly due to the fact that since 2012, the Chinese government has been building Guilin into a world-class landscape sightseeing spot, leisure resort, and exhibition and business tourism

Table 6. Values of ecosystem service functions in Guilin (ten thousand yuan).

\begin{tabular}{|c|c|c|c|c|c|c|}
\hline Year & Forest land & Cultivated land & Water & Unused land & Grassland & Total \\
\hline 2002 & 40086.52 & 2877.85 & 3538.29 & 232.53 & 249.23 & 46984.42 \\
\hline 2012 & 41286.24 & 2979.12 & 3488.00 & 205.16 & 179.20 & 48137.72 \\
\hline 2017 & 42996.21 & 3015.46 & 3587.89 & 159.95 & 248.16 & 50007.67 \\
\hline 15 -year variation & 2909.69 & 137.61 & 49.60 & -72.58 & -1.07 & 3023.26 \\
\hline
\end{tabular}


destination, causing a significant increase in the area of construction land and grassland from 2012 to 2017.

Unused land had the fastest reduction rate among land use types, and its dynamic degree was $-2.08 \%$. The GDP of Guilin has increased from 35.76 billion yuan in 2002 to 204.51 billion yuan in 2017, with an average annual growth of 11.25 billion yuan. At the same time, the resident population of the study area has increased from 4,876,200 in 2002 to 5,057,500 in 2017. The rapid development of the economy and the increase in the population inevitably increased the occupation of unused land and eventually caused the transfer of unused land to other types of land use.

The change rate of forest land, water, and cultivated land area was relatively slow, which is related to the policy of adhering to ecological environmental protection and building an "ecological and harmonious Guilin" for many years.

According to Formula (3), the comprehensive dynamic degree of land use in the study area in 2 002-2012 and 2012-2017 was obtained with the values of $2.72 \%$ and $8.09 \%$, respectively. It was found that the comprehensive dynamic degree of land use in the two periods was on the rise, indicating that the change rate of land use in the study area was continuing to accelerate, the land use intensity was greater, and the overall stability was worse.

\section{Changes in the Ecosystem Services Value of Various Land Use Types}

The ecosystem services value and contribution rates of different land use types in Guilin from 2002 to 2017 are shown in Table 6. Over 15 years, the value of ecosystem services in Guilin has been on the rise. Its services value has increased by 3023.26 ten thousand yuan, with an average annual growth of 201.55 ten thousand yuan. From the perspective of land use types, the services value of forestland increased the most. Compared with forest land, the service values of cultivated land and water also showed an increasing trend, with an increase of 137.61 and 49.60 ten thousand yuan, respectively. However, the value of ecosystem services on unused land and grassland

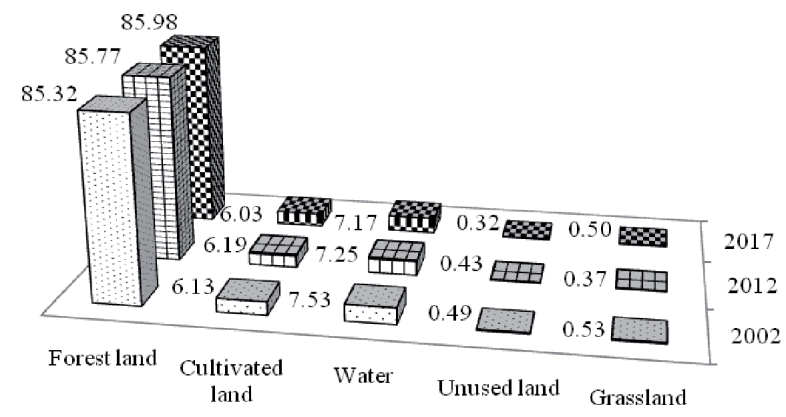

Fig. 3.Contribution rates of ecosystem service values in different land use types from 2002 to 2017 in Guilin (\%).

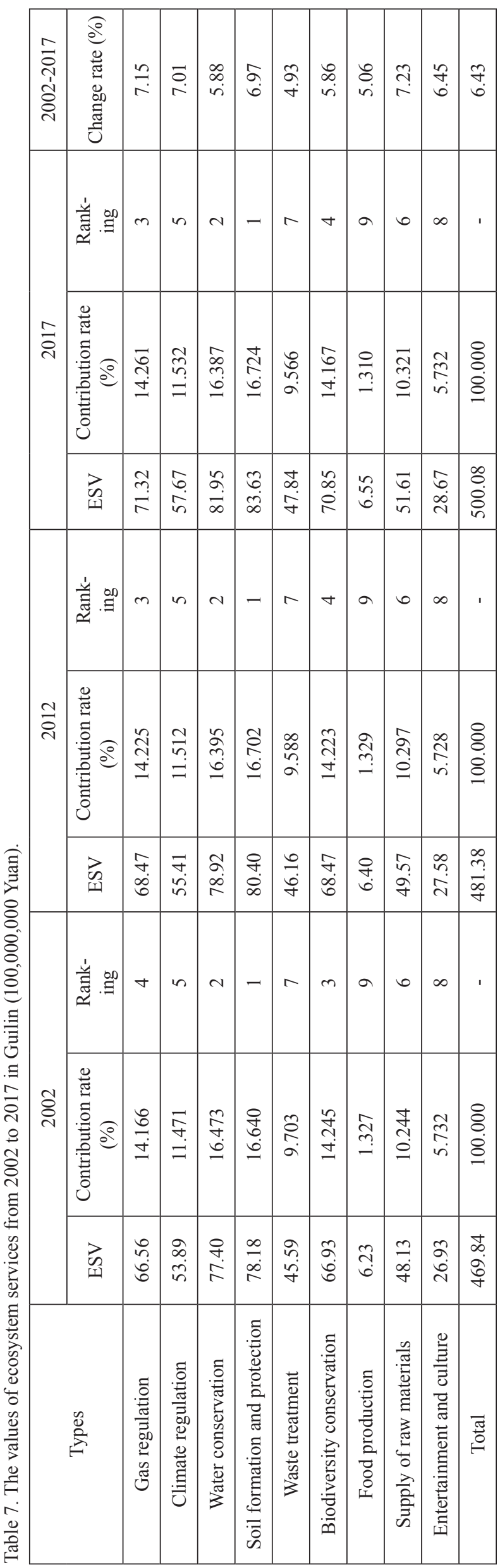


showed a downward trend over 15 years, dropping by 72.58 and 1.07 ten thousand yuan, respectively. The changes in the value of ecosystem services for each of the six land use types were determined by their area changes.

Fig. 3 indicates that the contribution rate of forest land to the total value of ecosystem services in Guilin was more than $85 \%$, while the contribution rate of the ecosystem services value of other land use types was lower, with a value of under $8 \%$. The contribution rates of unused land and grassland were less than $1 \%$.

\section{Changes in the Value of Individual Services in the Ecosystem}

Table 7 shows that the values of all individual services in the ecosystem increased during the studied period, and the rate of change in the value of the services such as raw materials, gas regulation, and climate regulation has exceeded $7 \%$. Despite the value of waste treatment services being the lowest, it still exceeded 4\%. The results are closely related to the government's continuous implementation of ecological forestry and protection of the biodiversity of the Guilin Lijiang River Basin.

Table 7 indicates that the value type and contribution rate of individual services was generally soil formation and protection $>$ water conservation $>$ biodiversity conservation $>$ gas regulation $>$ climate regulation $>$ raw materials $>$ waste treatment $>$ entertainment culture $>$ food production. In particular, the sum of the contribution rates of soil formation and protection, water conservation, biodiversity conservation, and gas regulation was greater than $60 \%$ - mainly owing to the area of forest land, with its higher value of soil formation and protection and water conservation, accounting for more than $60 \%$ of the whole study area. However, the contribution rate of food production was the lowest at less than $2 \%$, indicating that the service function of Guilin as a tourist city was far greater than its productive function.

\section{Conclusions}

In recent years, the process of urbanization in Guilin has been accelerating, and land resources are being continuously developed and utilized by human beings. Land use change affects the structures, functions, and processes of ecosystems by changing the type of surface cover, which in turn affects the supply of ecosystem services and the improvement of human well-being [28-30]. Quantitative assessment of the relationship between land use and the value of ecosystem services has become a hot topic in recent ecological research [31-33]. Therefore, based on a three-stage land use remote sensing data analysis, the changes in land use status and the value of ecosystem services in Guilin during the study period were quantitatively analyzed and the results showed the following.

Forest land was the main land matrix type in Guilin. During the study period, forest land showed the largest increase, while unused land showed the largest decrease. Forest land not only had a high retention rate, but also the transfer rate of other land types to forest land was greater. The transfer rate of unused land reached as high as $97.25 \%$, mainly shifting to forest land and cultivated land. Although the area of construction land and grassland did not change significantly during the whole study period, their area had changed rapidly between 2012 and 2017, indicating that policy had played a decisive role in the changes in these land use types.

During the study period, the value of ecosystem services in Guilin generally showed an upward trend. The contribution rate of forest land to the value of total ecosystem services was the greatest, while the service value of unused land and grassland declined. The increase in the area of forest land has resulted in a greater value of individual ecosystem services such as soil formation and protection, water conservation, biodiversity conservation, and gas regulation, which are closely related to forest land. Owing to the vast transfer of the remaining land use types to forest land, the increase in the value of forest ecosystem services was directly related to the transfer of other land use types. However, the value of food production services was the lowest, indicating that the service function of Guilin's ecosystem was far greater than its productive function.

\section{Acknowledgements}

The authors are grateful to the Specialized Research Fund for the Doctoral Program of Shaoyang University(fund No. 17ZX03).

\section{Conflict of Interest}

No conflict of interest exits in the submission of this manuscript, which has been approved by all authors for publication.

\section{References}

1. LEE S.J., LEE E.H., AN K.G. Lotic ecosystem health assessments using an integrated analytical approach of physical habitat, chemical water quality, and fish multimetric health metrics. Pol. J. Environ. Stud. 27 (5), 2113, 2018.

2. CETIN M. Determining the bioclimatic comfort in Kastamonu City. Environ. Monit. Assess. 187 (10), 640, 2015.

3. CETIN M. Evaluation of the sustainable tourism potential of a protected area for landscape planning: a case study of the ancient city of Pompeipolis in Kastamonu. Int. J. Sust. Dev. World. 22 (6), 490, 2015. 
4. CETIN M. Using GIS analysis to assess urban green space in terms of accessibility: case study in Kutahya. Int. J. Sust. Dev. World. 22 (5), 1, 2015.

5. GRIMM N.B., FAETH S.H., GOLUBIEWSKI N.E., REDMAN C.L., WU J., BAI X., BRIGGS J.M. Global change and the ecology of cities.Science. 319 (5864), 7 56, 2008

6. KELLY R., LEACH K., CAMERON A., MAGGS C.A., REID N. Combining global climate and regional landscape models to improve prediction of invasion risk. Divers. Distrib. 20 (8), 884, 2014.

7. CETIN M. Consideration of permeable pavement in Landscape Architecture. J. Environ. Prot. Ecol. 16 (1), 385, 2015.

8. CETIN M., ONAC A.K., SEVIK H., CANTURK U., AKPINAR H.Chronicles and geoheritage of the ancient Roman city of Pompeiopolis: a landscape plan. Arab. J. Geosci. doi: https://link.springer.com/article/10.1007/ s12517-018-4170-6, 2018

9. CETIN M., ADIGUZEL F., KAYA O., SAHAP A. Mapping of bioclimatic comfort for potential planning using GIS in Aydin. Environ. Develop. Sustain. 20 (1), 361, 2018.

10. MENDOZAGONZÁLEZ G., MARTÍNEZ M.L., LITHGOW D., PÉREZMAQUEO O., SIMONIN P. Land use change and its effects on the value of ecosystem services along the coast of the Gulf of Mexico. Ecol. Econ. 82 (20), 23, 2012.

11. ZHAND J.J., FU M.C., ZENG H., GENG Y.H.,HASSANI F.P. Variations in ecosystem service values and local economy in response to land use: a case study of Wu'an, China. Land Degrad. Dev. 24 (3),236, 2013.

12. LI G., FANG C. Global mapping and estimation of ecosystem services values and gross domestic product: A spatially explicit integration of national 'green GDP' accounting. Ecol. Indic. 46 (46), 293, 2014.

13. CETIN M., KALAYC ONAC A., SEVIK H., SEN B. Temporal and regional change of some air pollution parameters in Bursa. Air Qual. Atmos. Hlth. doi: https:// doi.org/10.1007/s11869-018-00657-6, 2018.

14. CETIN M. Sustainability of urban coastal area management: a case study on Cide. J. Sustain. Forest. 35 (7), 527, 2016.

15. KAYA E., AGCA M., ADIGUZEL F., CETIN M. Spatial data analysis with $\mathrm{R}$ programming for environment. Hum. Ecol. Risk Assess. doi: https://doi.org/10.1080/10807039.20 18.1470896, 2018.

16. KLEIJN D., KOHLER F., BÃLA., BATÃ R.P., CONCEPCIÃ N., CLOUGH Y., DÃAZ M., GABRIEL D., HOLZSCHUH A., KNOP E. On the relationship between farmland biodiversity and land-use intensity in Europe. Proc. Biol. Sci. 276 (1658), 903, 2009.

17. NEWBOLD T., HUDSON L.N., HILL S.L., CONTU S., LYSENKO I., SENIOR R.A., BÖRGER L., BENNETT D.J, CHOIMES A., COLLEN B.Global effects of land use on local terrestrial biodiversity. Nature. 520 (7545), 45, 2015.

18. LIN W., LI Y., LI X., XU D. The dynamic analysis and evaluation on tourist ecological footprint of city: take Shanghai as an instance.Sustain. Cities Soc. 37, 541, 2018.

19. WANG X.D., ZHONGX.H., GAOP. A GIS-based decision support system for regional eco-security assessment and its application on the Tibetan Plateau. J. Environ. Manage. 91 (10) 1981, 2010.

20. SHI G., JIANG N., YAO L. Land use and cover change during the rapid economic growth period from 1990 to 2010: a case study of Shanghai. Sustainability. 10 (2), 426, 2018.

21. WANG Y., YU X., HE K., LI Q., ZHANG Y., SONG S.Dynamic simulation of land use change in Jihe watershed based on CA-Markov model. T. Chinese Soc. Agr. Eng. 27 (12), 330, 2011.

22. XIE, G.D., ZHEN L., LU C.X., XIAO Y.,CHEN C. Expert knowledge based valuation method of ecosystem services in China.J. Nat. Resour. 23 (5), 911, 2008.

23. LIU G., ZHANG L.,ZHANG Q. Spatial and temporal dynamics of land use and its influence on ecosystem service value in Yangtze River Delta. Acta Ecol. Sin. 34 (12), 3311, 2014

24. RONG Y., CHAO L.I., CE X.U., YAN Y. Ecosystem service values and spatial differentiation changes during urbanization: A case study of Huanghua City. Chinese J. Ecol. 36 (5),1374, 2017.

25. XIE G.D., ZHANG C.X., ZHANG L.M., CHEN W.H., LIS.M. Improvement of the evaluation method for ecosystem service value based on per unit area. J. Nat. Resour. 30 (8), 1243, 2015.

26. COSTANZA R., GROOT R.D., SUTTON P., PLOEG S.V.D., ANDERSON S.J., KUBISZEWSKI I., FARBER S., TURNER R.K., Changes in the Global Value of Ecosystem Services. Global Environ. Chang. 26 (1), 152, 2014.

27. QIAO W., SHENG Y., FANG B.Land use change information mining in highly urbanized area based on transfer matrix: A case study of Suzhou, Jiangsu Province. Geogr. Res. 32 (8),1497, 2013.

28. GAGLIO M., ASCHONITIS V.G., GISSI E., CASTALDELLI G., FANO E.A. Land use change effects on ecosystem services of river deltas and coastal wetlands: case study in Volano-Mesola-Goro in Po river delta (Italy). Wetl. Ecol. Manag. 25 (1), 67, 2017.

29. POLASKY S., NELSON E., PENNINGTON D.,JOHNSON K.A. The impact of land-use change on ecosystem services, biodiversity and returns to landowners: a case study in the State of Minnesota. Environ. Resour. Econ. 48 (2), 219, 2011.

30. RODRÍGUEZ-ECHEVERRY J., ECHEVERRÍA C., OYARZÚN C., MORALES L. Impact of land-use change on biodiversity and ecosystem services in the Chilean temperate forests.Landscape Ecol. 5982, 1, 2018.

31. HAASE D., LARONDELLE N., ANDERSSON E., ARTMANN M., BORGSTRÖM S., BREUSTE J, GOMEZBAGGETHUN E., GREN Å., HAMSTEAD Z., HANSEN R.A quantitative review of urban ecosystem service assessments: concepts, models, and implementation. Ambio. 43 (4), 413, 2014.

32. LI,J.X., YANG L., YANG L., ZHANG C., HUOZ.M., CHEN M.H., LUAN X.F. Quantitative assessment of urban ecosystem services flow based on entropy theory: A case study of Beijing, China.Chinese J. Appl. Ecol. 29 (3), 987, 2018.

33. QUÉTIER F., LAVOREL S., THUILLER W., DAVIES I. Plant-trait-based modeling assessment of ecosystemservice sensitivity to land-use change. Ecol. Appl. 17 (8), 2377, 2007. 
